\title{
Effect of Chitosan Molecular Weight on the Performance of Chitosan-silica Nanoparticle System in Recycled Pulp
}

\begin{abstract}
Elmira Amiri, Mehdi Rahmaninia,* and Amir Khosravani
The application of chitosan biopolymer with and without nanoparticles in the papermaking process was investigated. The effect of the chitosan's molecular weight on its interaction with silica nanoparticles in recycled old corrugated container pulp was studied. Initially, the nanosilica particles were analyzed via atomic force microscopy and scanning electron microscopy, which confirmed the spherical shape of the silica nanoparticles with diameter less than $5 \mathrm{~nm}$. Dynamic light scattering method was used to determine the zeta potential and the hydrodynamic radius of the chitosan with different molecular weights. Infrared spectroscopy was used to show the possibility of hydrogen bonding between the chitosan and the nanosilica. The results showed that the chitosan with low and medium molecular weights in alkaline and in some neutral suspensions had better process performances. Increasing the molecular weights of the chitosan improved the mechanical properties. The influence of chitosan on the process parameters was dependent on different factors such as its configuration in the aqueous media before and after adsorption, its ability to penetrate the fiber pores, and its charge density. In contrast, the effect of chitosan on the strength of paper was influenced by its performance following adsorption and retention within the fibrous mat.
\end{abstract}

Keywords: Chitosan; Molecular weight; Nanosilica; Papermaking wet end; Recycled old corrugated container; Cellulosic fiber

Contact information: Department of Wood and Paper Science and Technology, Faculty of Natural Resources, Tarbiat Modares University, Iran; *Corresponding author: rahmaninia@modares.ac.ir

\section{INTRODUCTION}

Chitosan $(\mathrm{Ch})$ biopolymer is the product of the chitin de-acetylation process. This valuable biopolymer is a linear polysaccharide which has $\alpha(1 \rightarrow 4)$-linked 2-amino-2deoxy-ß-D-glucose bonds and is able to be dissolved in acidic aqueous solutions to produce a cationic polyelectrolyte. As a nontoxic, biocompatible, antifungal, and antibacterial biopolymer, Ch possess a considerable number of amino groups in its structure (Deng et al. 2011, 2012; Kim et al. 2017). The similar molecular structures of Ch and cellulose have created strong compatibility between the two valuable biopolymers (Nicu et al. 2011; Rohi et al. 2016).

As a cationic polyelectrolyte, Ch has various applications in the papermaking industry (Huang et al. 2007; Ashori et al. 2013; Rahmaninia et al. 2018). Chitosan can be particularly useful in recycled cellulosic pulps with critical conditions (higher conductivity, existence of more undesirable substances, higher fiber fines content, and weaker fibers in comparison with virgin pulp) (Rahmaninia et al. 2008; Rahmaninia and Khosravani 2015). Old corrugated container (OCC) is one of the most abundant waste paper grades. Therefore, 
much attention has been given to improving the process and product properties of OCC (Hamzeh et al. 2013; Rahmaninia et al. 2016).

Currently, the application of nanoparticles with polyelectrolytes (as nanoparticle systems) is common for improving the drainage and fines retention of papermaking systems (Carr and Tokarz, 2006; Cho et al. 2006; Khosravani and Rahmaninia 2013). In this regard, colloidal nanosilica is one of the most popular and important nanoparticles used in papermaking, due to its tiny dimensions and high specific surface area. These spherical nanoparticles may have a specific surface area in the range of 500 to $1200 \mathrm{~m}^{2} / \mathrm{g}$ and high anionic charge, which allows them to interact with cationic long chain polyelectrolytes (Hubbe 2005).

Polyelectrolytes are an important complement in the nanoparticle system. It is expected that $\mathrm{Ch}$ biopolymer with special characteristics, such as abundant amino groups and a linear structure, can be a prospective alternative as a cationic polyelectrolyte in this system (Alince et al. 1996; Jahan et al. 2009; Sabazoodkhiz et al. 2017).

The molecular weight (MW) and de-acetylation degree (DD) of $\mathrm{Ch}$ varies according to its synthesis methods and production conditions. Therefore, the MW of $\mathrm{Ch}$ ranges from 100 to 1100 kilodaltons, and its DD ranges from 67\% to 95\% (Hwang et al. 2002). The variability of the MW and DD affects the characteristics and applications of $\mathrm{Ch}$ (Li et al. 2004; Myllytie et al. 2009).

Previous studies have investigated the MW of chitosan and its effect on the flocculation in pulp suspensions and process properties in single $\mathrm{Ch}$ and Ch-bentonite systems (Agusnar et al. 2013; Nicu et al. 2013; Habibie et al. 2016; Miranda et al. 2016; Vikele et al. 2017). Considering the drainage performance, low molecular weight (LMW) of Ch showed the best results (Agusnar et al. 2013; Miranda et al. 2016).

Previous studies also indicated that the single application of MMW Ch was more effective in improving the mechanical properties of paper compared to LMW Ch (Agusnar et al. 2013; Vikele et al. 2017). However, Habibie et al. (2016) reported that the single application of LMW Ch was more successful in improving the mechanical properties of paper rather than MMW Ch.

Vikele et al. (2017) reported that micro-Ch could easily fill the submicroscopic pores and voids in the porous structure of paper and had a greater impact on the dry strength. Alince et al. (1996) indicated that LMW polyethylenimine, in a similar manner, easily penetrated the pores and spaces between the components of the pulp suspension compared to the high MW (HMW) polyethylenimine. Moreover, as a nanoparticle system, LMW Ch has been successfully applied with silica nanoparticle for improving drainage and retention (Sabazoodkhiz et al. 2017).

Considering previous studies, there is an inconsistency about the effect of Ch MW (low, medium, and high) on its performance in various systems applied in pulp suspensions.

The authors' previous work on the Ch-nanosilica system has shown a proper performance in recycled suspension (Sabazoodkhiz et al. 2017). Considering the idea that the MW of Ch can influence its configuration in the pulp suspension, which then affects its penetration of fiber pores and the spaces between the components of the pulp suspension, the influence of $\mathrm{Ch} \mathrm{MW}$ in the mentioned nanoparticle system needs to be investigated.

Therefore, this study considers the effect of Ch MW on the performance of Chnanosilica system in the recycled pulp. 


\section{EXPERIMENTAL}

\section{Materials}

The OCC was collected from Noor city, Mazandaran providence, Iran. Chitosan with low, medium, and high MWs were purchased from Sigma-Aldrich (Steinheim, Germany). Table 1 shows the characteristics of the Ch types according to the supplier's data sheet. Aqueous $\mathrm{Ch}$ solution at a concentration of $0.5 \%(\mathrm{w} / \mathrm{w})$ was prepared by dissolving the $\mathrm{Ch}$ in $1 \%(\mathrm{w} / \mathrm{w})$ acetic acid at room temperature for $2 \mathrm{~h}$.

Table 1. Chitosan Characteristics

\begin{tabular}{|c|c|c|c|}
\hline Chitosan Type & $\begin{array}{c}\text { Degree of } \\
\text { Deacetylation }(\%)\end{array}$ & $\begin{array}{c}\text { Viscosity at } 24^{\circ} \mathrm{C} \\
\text { (cp) }\end{array}$ & MW (kDa) \\
\hline LMW & 75 to 85 & 20 to 300 & 100 to 120 \\
\hline MMW & 75 to 85 & 200 to 800 & 400 to 600 \\
\hline HMW & 75 to 85 & 800 to 2000 & 800 to 1100 \\
\hline
\end{tabular}

Colorless anionic nanosilica (Sol-type) colloid with $8.5 \%$ solids content, $15 \mathrm{cp}$ viscosity (at $24{ }^{\circ} \mathrm{C}$ ), and a specific surface area of $850 \mathrm{~m}^{2} / \mathrm{g}$ was purchased from EKA Paper Chemicals (Marietta, GA, USA) under the commercial name NP320. The Ch and nanosilica dosages were $1 \%$ and $0.1 \%$ (w/w) (based on oven-dry (OD) weight of the pulp), respectively, according to optimum dosages of previous works (Sabazoodkhiz et al. 2017). The control sample did not contain any additive.

\section{Methods}

Characterization of nanosilica

An atomic force microscope (AFM) (Easyscan 2 Flex; Nanosurf, Liestal, Switzerland) was used for the size distribution measurements. One drop of diluted nanoparticle $(0.05 \mathrm{mg} / \mathrm{mL})$ was poured onto a clean glass surface and dried at room temperature to prepare for microscopic imaging. The size dimensions and size distribution of the nanoparticle were observed and recorded with the analytical digital software in the apparatus (Nanosurf easyScan 2 Control Software, version 1.3., Switzerland).

For a more accurate analysis of the dimensions and the shape of the nanoparticles, field emission scanning electron microscope (FESEM) images were taken at various magnifications using a Mira3 XMU FESEM apparatus (TESCAN, Brno, Czech Republic), at an accelerating voltage of $10 \mathrm{kV}$.

\section{Determination of zeta potential and the hydrodynamic radius $(H R)$ of $C h$}

The dynamic light scattering method (DLS) was applied to determine the zeta potential and the HR of $\mathrm{Ch}$ with different MWs dissolved in $1 \%$ acetic acid. For this purpose, a Nano Zetasizer (Malvern Panalytical, Malvern, UK) was used.

\section{Chitosan and nanosilica probable interaction in suspension}

Fourier-transform infrared (FTIR) spectroscopy was applied to identify the possible interaction between $\mathrm{Ch}$ and nanosilica in alkaline conditions. For this purpose, the $0.5 \mathrm{~g}$ Ch solution prepared in $1 \%$ acid acetic (with $0.5 \%$ concentration) was mixed with $0.5 \mathrm{~g}$ nanosilica colloid (with $0.5 \%$ concentration). The mixture was in alkaline conditions. A Shimadzu FTIR 8400s (Shimadzu, Kyoto, Japan) was used for the FTIR analysis. A range of 4000 to $400 \mathrm{~cm}^{-1}$ was examined at a resolution of $4 \mathrm{~cm}^{-1}$ for 32 scans. 


\section{Preparation of the pulp suspension}

For the pulp preparation, $360 \mathrm{~g}$ (OD weight) of OCC was soaked in deionized water with $20 \mu \mathrm{s} / \mathrm{cm}$ conductivity for $24 \mathrm{~h}$. The fiber was disintegrated and refined up to $300 \pm$ $20 \mathrm{~mL}$. CSF (Canadian Standard Freeness) with a laboratory Valley beater (Siami Co., Karaj, Iran) based on the TAPPI T200 sp-01 (2001) standard. After preparation, the pulp was stored in a refrigerator until its use.

\section{Application of the nanoparticle system}

The chemicals were added in the pulp suspension with $0.5 \%$ consistency. The $\mathrm{Ch}$ was mixed with the pulp at $1000 \mathrm{rpm}$ for $45 \mathrm{~s}$. Then, nanosilica was added and mixed for $15 \mathrm{~s}$ at $800 \mathrm{rpm}$. The conductivity of the pulp before chemical addition was approximately $200 \mu \mathrm{s} / \mathrm{cm}$ at ambient temperature $\left(25^{\circ} \mathrm{C}\right)$.

\section{Handsheet preparation}

The paper handsheets were prepared based on the TAPPI T205 sp-02 (2002) standard. To prepare the $130 \mathrm{~g} / \mathrm{m}^{2}$ paper, $2.6 \mathrm{~g}$ of refined pulp (OD weight) was diluted to $0.5 \%$ consistency with deionized water. Following the chemical addition to the suspension, the handsheets were prepared in a mold handsheet maker. At least 10 sheets were produced for each treatment. Finally, the handsheets were dried using a cylindrical drier at $60{ }^{\circ} \mathrm{C}$ for $2.5 \mathrm{~h}$.

\section{Pulp drainage}

The pulp drainage was measured based on the TAPPI T227 om-04 (2004) standard, with the CSF tester. The pulp $\mathrm{pH}$ was considered as a variable $(5.5,7$, and 8.5) before application of the system and following each treatment, $3 \mathrm{~g}$ of furnish (OD weight) was poured into a graduated cylinder. Deionized water was added to the cylinder to reach a total volume of $1000 \mathrm{~mL}$. Then, the homogenized suspension was transferred to the freeness tester.

\section{Fines content}

The fines content was defined as the amount of solids in the furnish that passed through a 200-mesh screen. The fines content of the recycled furnish was measured based on the TAPPI T261 cm-00 (2000) standard using a Britt Dynamic Drainage Jar (BDDJ) (Paper Research Materials, Seattle, USA). The fines content of the suspension was calculated according to Eq. 1,

$$
F=\frac{A}{B \times C} \times 100
$$

where $F$ is the fines content by weight (\%), $B$ is the weight of original sample $(\mathrm{g}), C$ is the consistency $(\mathrm{g} / \mathrm{g})$, and $A$ is the weight of the fines collected on the filter paper $(\mathrm{g})$. The experiment was replicated three times and the average fines content $(\%)$ of the pulp was measured as $48.22 \%$.

\section{Fines retention}

The first pass retention of the fines was calculated according to TAPPI T261 cm00 (2000) standard using a BDDJ. For this purpose, $500 \mathrm{~mL}$ of pulp suspension at a consistency of $0.5 \%$ was transferred to the BDDJ. After the $\mathrm{pH}$ adjustment (in 3 levels: 
5.5, 7, and 8.5) and the addition of chemicals, the filtrate was collected while being agitated at $750 \mathrm{rpm}$ for $30 \mathrm{~s}$. The fines retention was calculated according to Eq. 2,

$$
R=1-\frac{A \times W}{U \times T}
$$

where $T$ is the total fines in the sample $(\mathrm{g}), R$ is the fines retention $(\%), U$ is the weight of the filtrate (g), $W$ is the weight of the solids (fines) in the filtrate $(\mathrm{g})$, and $A$ is the weight of the original sample $(\mathrm{g})$.

\section{Mechanical properties}

The tensile index according to TAPPI T494 om-01(2001), the tear index according to TAPPI T414 om-04 (2004), the burst index according to TAPPI T403 om-02 (2002), and the internal bonding strength according to TAPPI T569 pm-00 (2000) were evaluated (Sabazoodkhiz et al. 2017).

\section{Statistical analysis}

Each treatment was tested at least three times. The results were statistically analyzed using a completely randomized design (CRD), and the standard deviations were calculated. Duncan's multiple range test (DMRT) was applied to categorize the averages. The Duncan grouping results were categorized alphabetically. The data groups that did not share the same letter were found to be significantly different from each other $(99 \%$ confidence level). The statistical analysis was conducted using SPSS software (IBM, version 16.0, Armonk, NY, USA).

\section{RESULTS AND DISCUSSION}

\section{Characterization of Silica Nanoparticles}

AFM analysis

The topography and dimensions of the silica nanoparticles were studied using AFM (Fig. 1). According to Fig. 1, the size of the silica nanoparticles ranged from $1 \mathrm{~nm}$ to $5 \mathrm{~nm}$.

\section{FESEM analysis}

The nanosilica dimensions were investigated further with FESEM images. Figure 2 demonstrates the nanosize of the silica particles, which confirmed the results of the AFM technique. The large particles were agglomerated nanosilica particles due to the preparation steps of the FESEM images.

\section{Zeta potential and the HR of chitosan}

Table 2 shows the zeta potential and the HR of the low and high MW Ch determined by the DLS method.

Table 2. Zeta Potential and the HR of Low and High MW Ch

\begin{tabular}{|c|c|c|}
\hline Molecular Weight & Zeta Potential $(\mathrm{mV})$ & $\mathrm{HR}(\mathrm{nm})^{\star}$ \\
\hline Low & +86 & 115 \\
\hline High & +90 & 112 \\
\hline
\end{tabular}

Hydrodynamic Radius (HR) 
The zeta potential was positive in both the low and high MW $\mathrm{Ch}$, which was a result of the increased number of protonated amine groups dissolved in $1 \%$ acetic acid. The HR values in both MWs were in the same range.
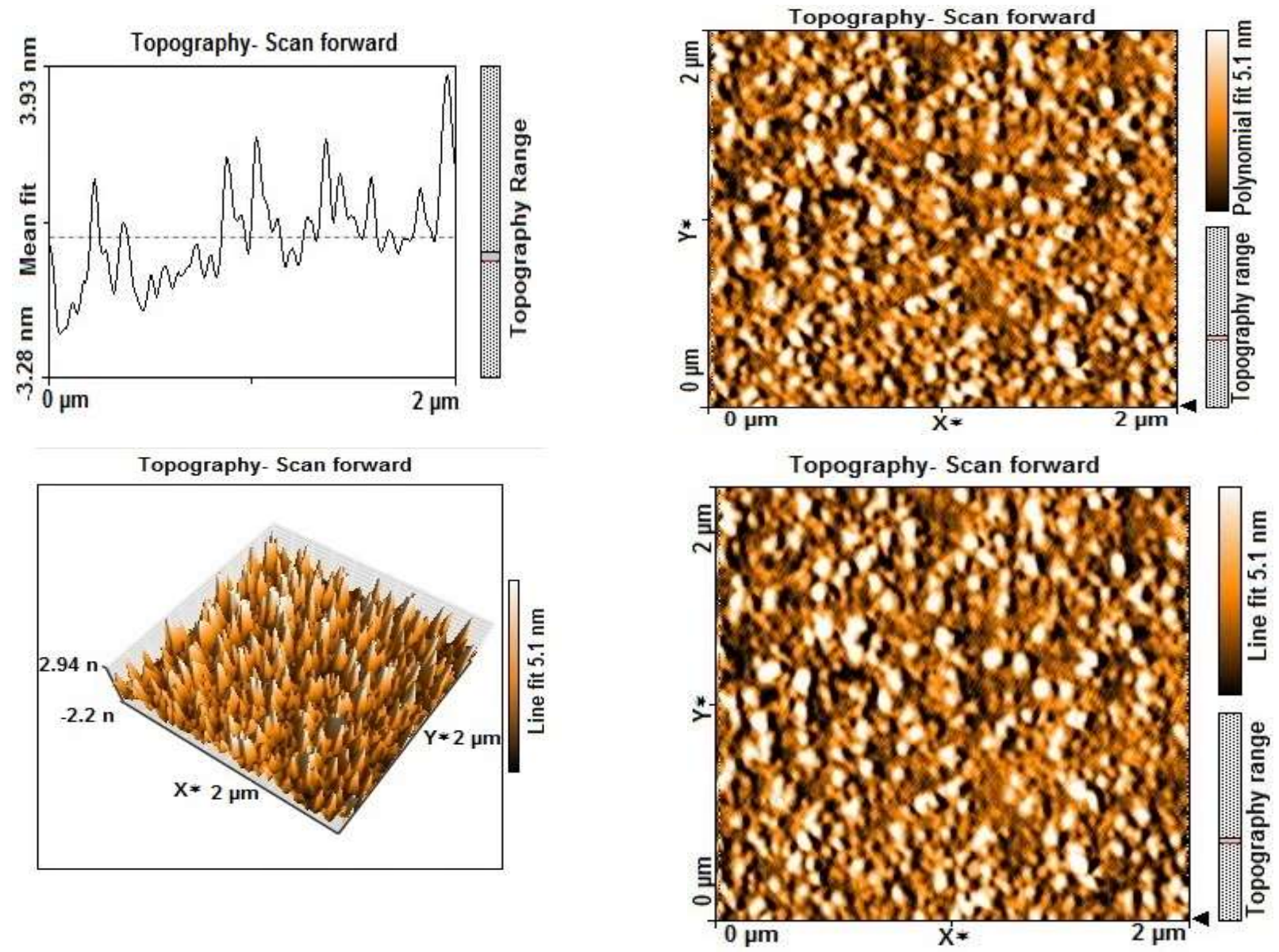

Fig. 1. Silica nanoparticles topography and diameter size estimation with the AFM images

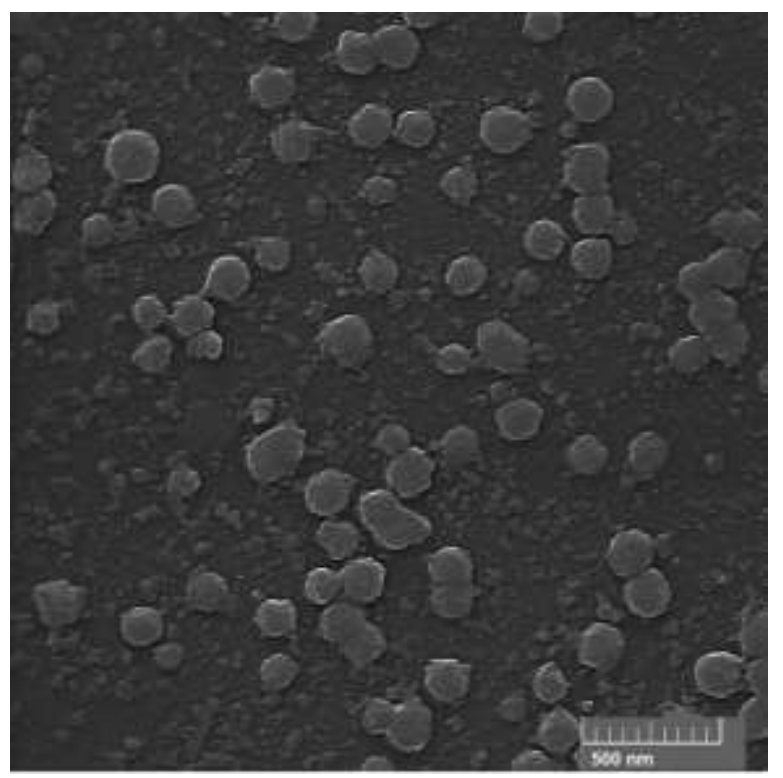

Fig. 2. The FESEM image of the spherical nanosilica (magnitude: $75 \mathrm{kx}$ ) 


\section{FTIR spectroscopy of nanosilica, Ch, and Ch-nanosilica}

The probable interaction between the nanosilica and the Ch was evaluated using FTIR spectroscopy. The FTIR spectroscopic data from the nanosilica can be seen in Fig. 3.

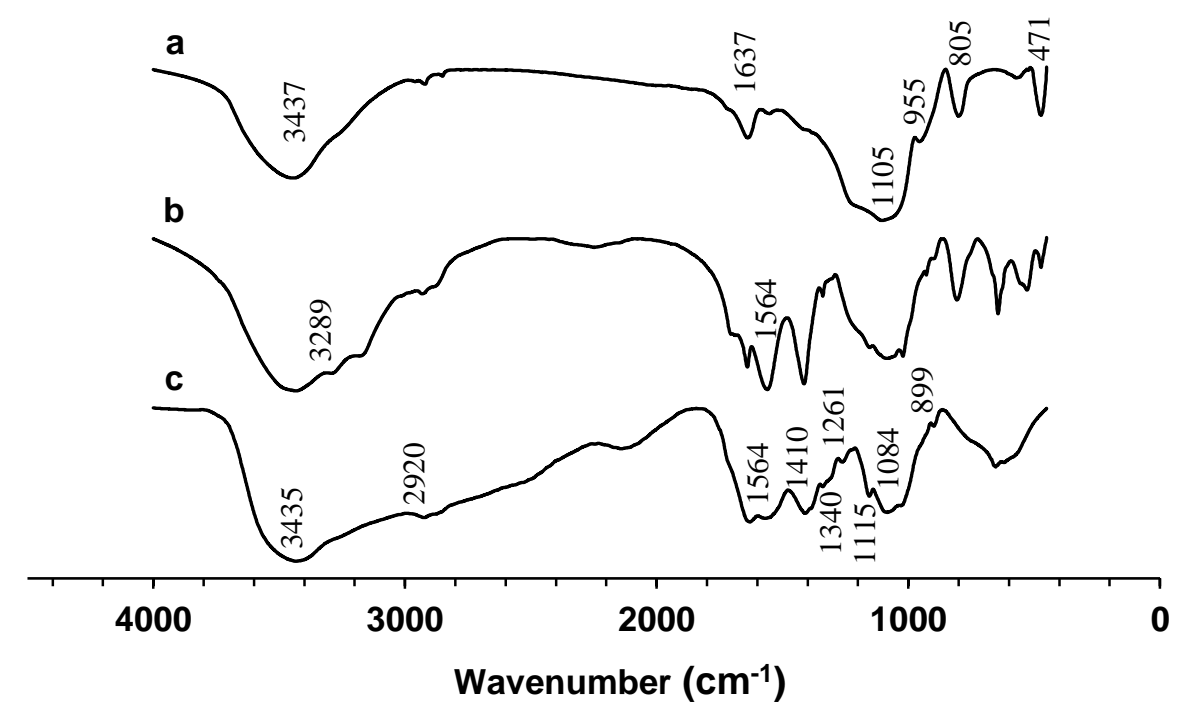

Fig. 3. The FTIR spectroscopy of (a) nanosilica, (b) Ch-nanosilica, and (c) Ch

The FTIR spectra of $\mathrm{Ch}$ and nanosilica have been investigated in a previous study (Sabazoodkhiz et al. 2017). The FTIR spectra of the Ch-nanosilica interaction in alkaline $\mathrm{pH}$ showed that the peak at $3435 \mathrm{~cm}^{-1}$ in $\mathrm{Ch}$, which corresponds to the stretching vibration of the O-H groups, overlapped with the stretching vibration of $\mathrm{N}-\mathrm{H}$. This indicated a double peak in the Ch-nanosilica mixture in alkaline condition. The peak at $3289 \mathrm{~cm}^{-1}$ is possibly related to shifting due to the hydrogen bonding between the $\mathrm{OH}$ of silanol groups on the nanosilica surface and the $\mathrm{OH}$ or $\mathrm{NH}_{2} \mathrm{Ch}$ (Budnyak et al. 2015).

\section{The Effect of Chitosan MW on the Nanoparticle System Performance}

\section{Drainage and fines retention parameters}

During the production of paperboard, dewatering from the wet web is critical due to the high basis weight of the web. Improving the drainage has many advantages for the paper industry. Some advantages include increasing the machine speed and productivity, reducing energy consumption, and finally lower production costs (Scott 1996). Paper machine drainage is largely affected by the retention system and the structure of the flocs. Fiber-fiber, fiber-fine, and fine-fine relations are all important to be considered (Khosravani et al. 2010). When fines (total particles below $76 \mu \mathrm{m}$ ) is a large portion of furnish, their retention in the final sheet is more important. In this study, fines content was about $48.2 \%$ of furnish, and thus retention was a critical factor.

The performance of $\mathrm{Ch}$ as a polyelectrolyte in combination with nanosilica (nanoparticle system) on the drainage and retention is observable in Table 3. The probable mechanism of chitosan-nanosilica interaction in pulp suspension has been explained elsewhere (Sabazoodkhiz et al. 2017). The cited article emphasized the forming of proper flocs in the pulp slurry based on a semi-reversible bridging mechanism. 
Because the $\mathrm{pH}$ of the fibrous suspension may highly affect the performance of the $\mathrm{Ch}$ as a polyelectrolyte, the data was analyzed under different $\mathrm{pH}$ conditions.

Table 3. The Effect of $\mathrm{pH}$ on Ch-nanosilica Performance in Process Properties

\begin{tabular}{|c|c|c|c|c|c|c|c|c|c|}
\hline & \multicolumn{3}{|c|}{ LMW Ch } & \multicolumn{3}{c|}{ MMW Ch } & \multicolumn{3}{c|}{ HMW Ch } \\
\hline $\mathrm{pH}$ & 5.5 & 7 & 8.5 & 5.5 & 7 & 8.5 & 5.5 & 7 & 8.5 \\
\hline $\begin{array}{c}\text { Drainage } \\
(\mathrm{mL} \text { CSF) }\end{array}$ & $\begin{array}{c}233 \\
(\mathrm{e}){ }^{*}\end{array}$ & $\begin{array}{c}303 \\
(\mathrm{bc})\end{array}$ & $\begin{array}{c}383 \\
(\mathrm{a})\end{array}$ & $\begin{array}{c}291 \\
(\mathrm{c})\end{array}$ & $\begin{array}{c}389 \\
(\mathrm{a})\end{array}$ & $\begin{array}{c}373 \\
(\mathrm{a})\end{array}$ & $\begin{array}{c}252 \\
(\mathrm{~d})\end{array}$ & $\begin{array}{c}321 \\
(\mathrm{~b})\end{array}$ & $\begin{array}{c}317 \\
(\mathrm{~b})\end{array}$ \\
\hline $\begin{array}{c}\text { Standard } \\
\text { Deviation }\end{array}$ & 6.39 & 8.76 & 8.60 & 8.94 & 17.89 & 10.44 & 8.94 & 14.45 & 2.51 \\
\hline $\begin{array}{c}\text { Retention } \\
(\%)\end{array}$ & - & $\begin{array}{c}69.7 \\
(\mathrm{~d})\end{array}$ & $\begin{array}{c}79.03 \\
(\mathrm{a})\end{array}$ & $\begin{array}{c}72.91 \\
(\mathrm{~cd})\end{array}$ & $\begin{array}{c}77.99 \\
(\mathrm{ab})\end{array}$ & $\begin{array}{c}75.08 \\
(\mathrm{bc})\end{array}$ & $\begin{array}{c}61.2 \\
8(\mathrm{f})\end{array}$ & $\begin{array}{c}65.64 \\
(\mathrm{e})\end{array}$ & $\begin{array}{c}66.0 \\
(\mathrm{e})\end{array}$ \\
\hline $\begin{array}{l}\text { Standard } \\
\text { Deviation }\end{array}$ & - & 1.85 & 0.32 & 1.18 & 1.65 & 1.65 & 1.30 & 1.56 & 1.07 \\
\hline $\begin{array}{l}\text { *The data that do not share the same letter in parentheses were found significantly } \\
\text { different from each other (99\% confidence level) }\end{array}$ \\
\hline
\end{tabular}

The results in Table 3 indicated that better drainage and retention was obtained in alkaline and neutral conditions. Some studies investigated $\mathrm{Ch}$ alone or $\mathrm{Ch}$ micro/nanoparticles in acidic conditions (Ashouri et al. 2006; Sabazoodkhiz et al. 2017; Rahmaninia et al. 2018). But this research showed that $\mathrm{Ch}$ performed better in alkaline and neutral conditions in combination with nanosilica. It seems that the presence of too much active amine groups in chitosan structure results in its very high positive charge in acidic condition (Rohi et al. 2016), so increasing the $\mathrm{pH}$ can reduce the charge density of the $\mathrm{Ch}$ to an optimum level. In this manner the Ch configuration tends to be in a loop and tail shape rather than flat one. This provides a greater chance for this bio-polyelectrolyte to bridge between the fines and fibers (Fig. 4) (Saarinen 2008).

Moreover, increasing the $\mathrm{pH}$, induces more negative charge to the fibers surface due to the de-protonation of the carboxyl groups. Thus, more cationic polyelectrolyte is able to adsorb onto the fibers (Scott 1996).
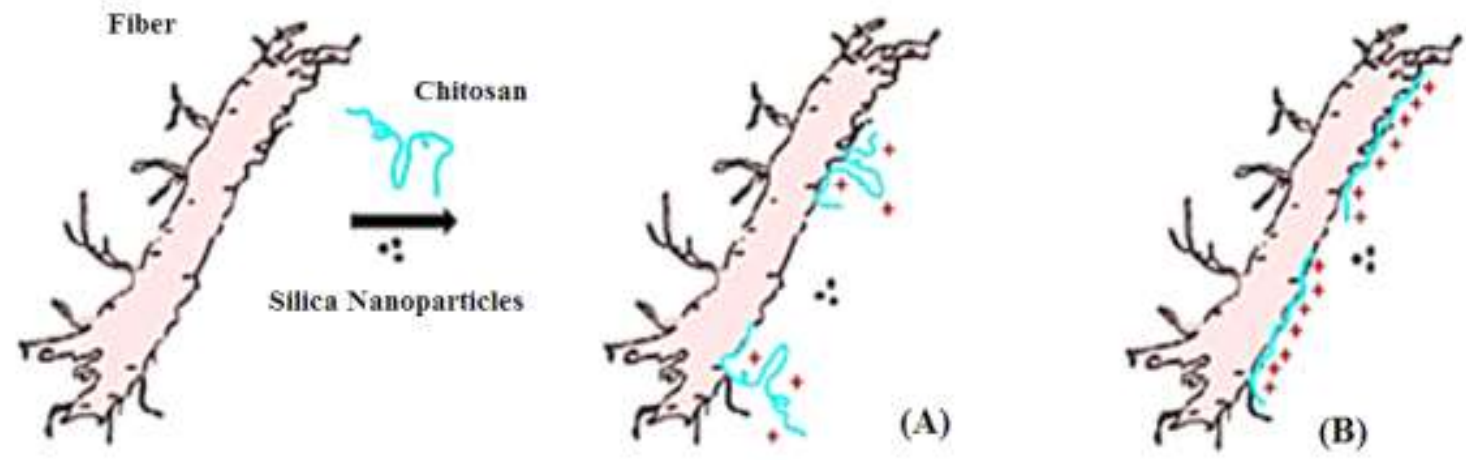

Fig. 4. Possible configuration states of $\mathrm{Ch}$ in (a) alkaline $\mathrm{pH}$ and (b) acidic $\mathrm{pH}$ 
Considering the effect of MW on drainage and retention, the best results were obtained from LMW Ch and MMW Ch. Agusnar et al. (2013) and Miranda et al. (2016) support this observation, which showed that LMW Ch and MMW Ch had the best and second-best drainage gains, respectively. In a dual system, Miranda et al. (2016) reported that the best drainage results were obtained by LMW Ch.

It was expected that HMW Ch would yield better drainage and fines retention due to its longer chain and better bridging ability. However, the HMW $\mathrm{Ch}$ was unable to penetrate the fiber pores and the spaces between the components of the pulp suspension (Alince et al. 1996; Vikele et al. 2017). This electrostatically enabled the maximum soluble polymers to adsorb on top of the fiber pores, causing the zeta potential of the suspension to be positive. A positive zeta potential can deteriorate the performance of the nanoparticle system and the formation of fiber flocs.

As optimum drainage and retention was obtained in alkaline conditions for $\mathrm{Ch}$ of various MWs and also paper machines are generally run in alkaline conditions, so the mechanical properties were evaluated for this $\mathrm{pH}$.

\section{Mechanical Properties of Paper Sheets} Apparent density

The effects of Ch MW on the apparent density of the recycled paper treated with the nanoparticle system are shown in Fig. 5. The MW had little effect on the density of the samples. This was attributed to the grammage to thickness ratio. The use of retention aids increased the grammage through better fines retention, while the formation of flocs increased the thickness (Hubbe 2006). Therefore, the apparent density (grammage to thickness ratio) did not change. However, it should be mentioned that according to the previous studies, the nano/microparticle systems will deteriorate the formation and uniformity of paper less than other common retention aids such as cationic polyacrylamide single polymer system (Sabazoodkhiz et al. 2017; Yousefhashemi et al. 2019).

\section{Tear index}

The tear index has a significant role in the ability of paper to pass through the papermaking machine and go through the converting process. The fundamental factors affecting the tear index are the fiber length, the inherent fiber strength, the bonding ability of the fibers, and the fiber orientation in sheet (Kermanian et al. 2013). Generally, in pulps with low bonding ability, such as mechanical pulps, tear strength can be improved by increasing the surface bonding. However, in pulps with high internal bonding, the limiting factors are the fiber length and the strength of the individual fibers.

The nanoparticle system had no effect on the fiber length and the strength of individual fibers. Therefore, the nanoparticle system may only increase the tear strength by increasing the bonding area in the paper sheet.

As shown in Fig. 5, the different treatments had little effect on the tear strength. At first glance, it was concluded that the Ch-nanosilica did not affect the tear strength. However, it is important to consider that by applying this system, more fines and fillers will be retained in the handsheets. The increased fine and filler content can decrease the tear strength considerably. Therefore, the lack of change in the tear index was attributed to both increasing in bonding area and increasing in retention of fines and fillers. 


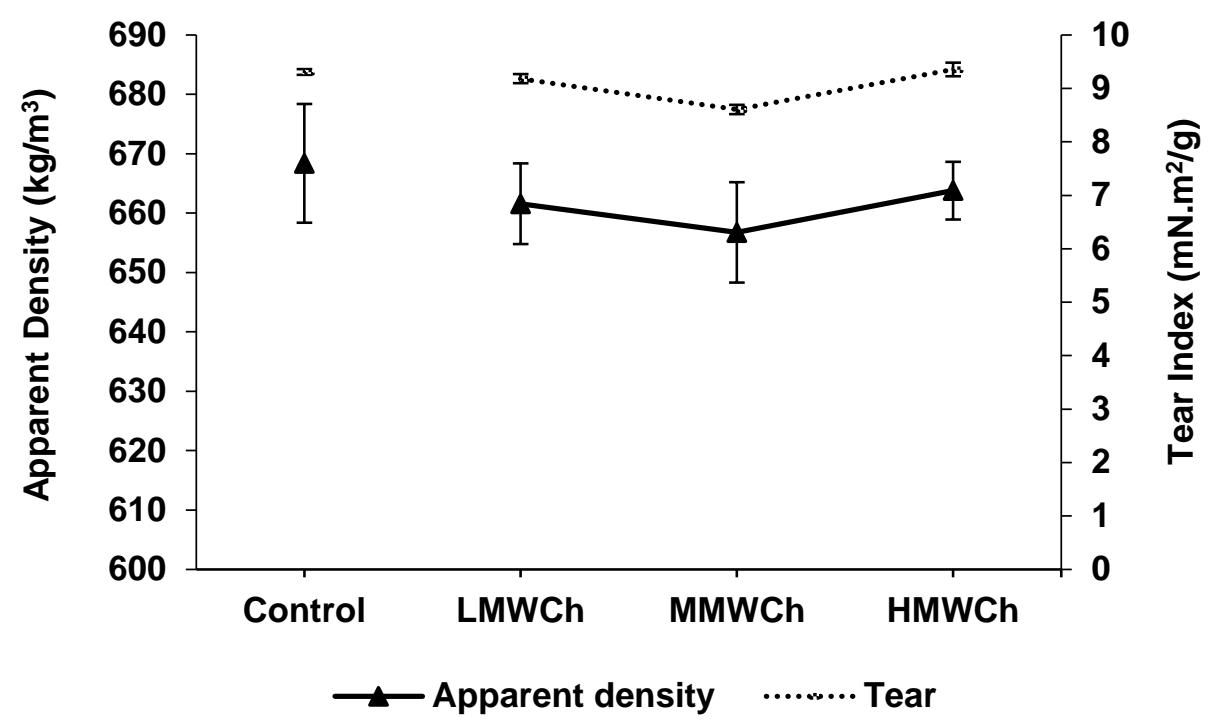

Fig. 5. The effects of Ch MW on the tear index and the apparent density

\section{Tensile and burst indices}

Figure 6 shows the tensile and burst indices of the samples treated with nanoparticle system containing different $\mathrm{MW} \mathrm{Ch}$. These samples were compared to the control treatment. The tensile and burst indices are critical properties that can be affected by the inherent fiber strength, the bonding strength of the fibers, the bonding area, the fiber distribution, and the sheet formation quality. The individual fiber strength is affected by the wood species, the pulping process, the bleaching process, and the amount of times the fibers have been recycled. Therefore, wet end additives in the papermaking process have little effect on the individual fiber strength. However, chemical treatments, such as wet end additives, can influence the distribution of fibers and the bonding capabilities (Kermanian et al. 2013). As demonstrated in Fig. 6, both the tensile and burst indices increased in all of the treated samples compared to the control treatment.

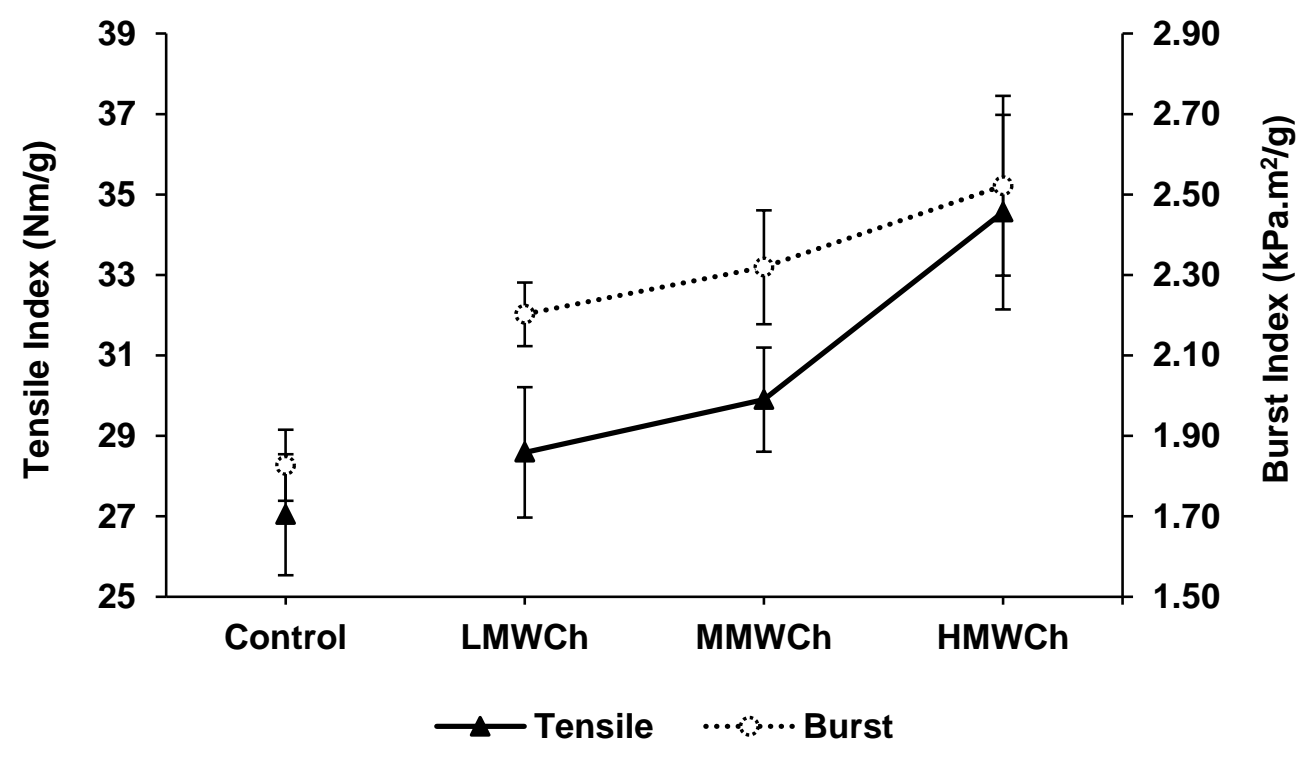

Fig. 6. The effects of Ch MW on the tensile index and the burst index 
The increase in strength was attributed to the performance of the nanosilica system. Previous research indicated that using additives, especially polyelectrolytes, in pulp suspensions can deteriorate the paper formation due to the formation of fiber flocs (Hubbe 2006). However, the positive performance of the Ch-nanoparticle in treated samples was due to the unique characteristics of $\mathrm{Ch}$. Chitosan has a similar structure to cellulose, along with active hydroxyl and amino groups. This allows for more bonding among the fibers and fines, which improves the bonding area in the paper sheet.

As the MW of the Ch samples increased, the tensile and burst indices increased as well. This was explained by the longer chain of high $\mathrm{MW} \mathrm{Ch}$, which provided more bonding sites for fibers and fines. Agusnar et al. (2013) and Vikele et al. (2017) indicated that the single application of MMW $\mathrm{Ch}$ had better results compared to the LMW Ch. However, Habibie et al. (2016) reported that the single application of LMW Ch was more successful than MMW Ch in improving the mechanical properties of paper.

\section{Internal bond index}

The results for the internal bond index (Scott bond) are shown in Fig. 7. According to these results, the internal bond strength increased using the Ch-nanosilica in all the MW levels of $\mathrm{Ch}$. As a polyelectrolyte with active functional groups, such as hydroxyl and amino groups, Ch can improve the internal bonding through means of hydrogen bonding, while also acting as an effective dry strength additive. Moreover, nanosilica may help to improve the internal bond strength due to the formation of smaller and denser flocs (Khosravani and Rahmaninia 2013).

Furthermore, increasing the MW of chitosan greatly improved the internal bond index. High MW chitosan has longer chains, which probably improve the chitosan ability to make more bridges among the solid components.

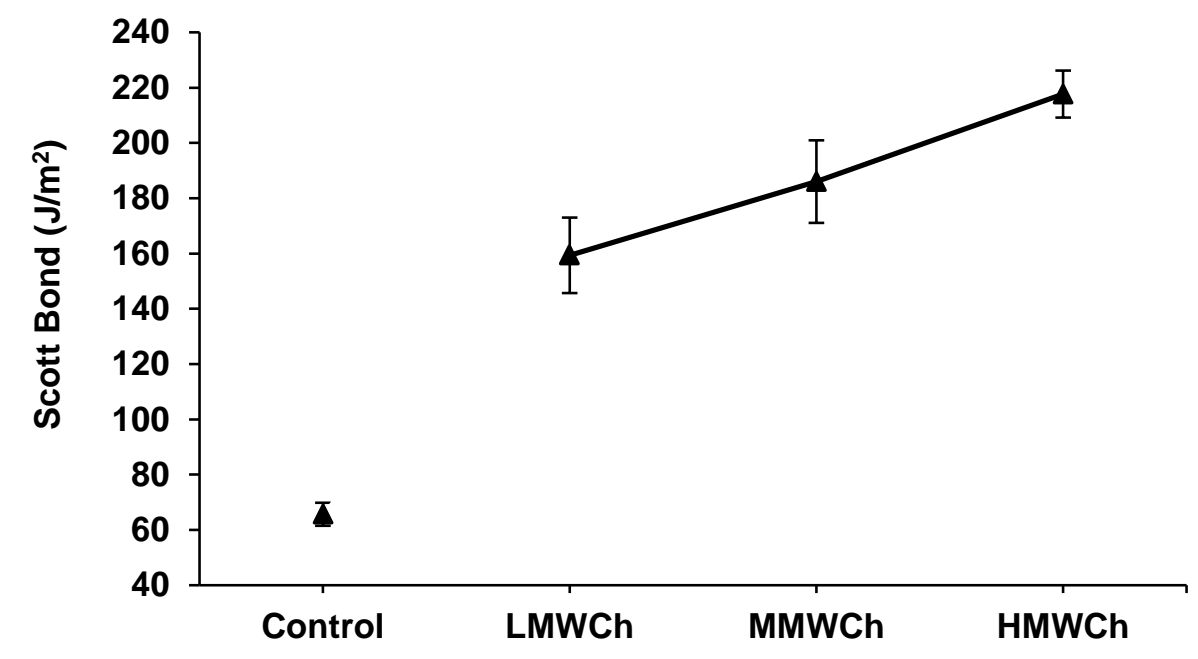

Fig. 7. The effects of Ch MW on the internal bond of paper 


\section{CONCLUSIONS}

1. The chitosan-nanosilica system improved the production process through increasing the fiber mat drainage and higher first pass retention. The optimum drainage and retention values were observed for the Ch of low and medium MWs. The interaction of this cationic polyelectrolyte with other components of the recycled pulp suspension was affected by its configuration in the aqueous media before and after adsorption, its ability to penetrate fiber pores, its charge density, and also the charge density of fibers. The interaction between the MW of $\mathrm{Ch}$ and the $\mathrm{pH}$ of the pulp suspension was also an important factor.

2. The best mechanical properties were obtained from the Ch of high MWs. The improved strength properties were likely attributable to Ch's performance following adsorption and retention within the fibrous mat, rather than the colloidal effects.

3. Previous studies have suggested that Ch usually works better in acidic conditions. However, this research showed that Ch-nanosilica performed better in alkaline conditions and to some extent in neutral conditions.

\section{ACKNOWLEDGMENTS}

The authors are grateful for the support of the Iran National Science Foundation (INSF) for Grant No. 93036049 and Tarbiat Modares University for providing some research laboratory equipment. The authors also are grateful to Dr. Omid Ramezani, Dr. Hossein Kermanian, and Engineer Zahra Razmpour for laboratory support at Shahid Beheshti University.

\section{REFERENCES CITED}

Agusnar, H., Nainggolan, I., and Sukirman. (2013). "Mechanical properties of paper from oil palm pulp treated with chitosan from horseshoe crab," Advances in Environmental Biology 7(12), 3857-3860.

Alince, B., Vanerek, A., and Van De Ven, T. G. M. (1996). "Effects of surface topography, $\mathrm{pH}$ and salt on the adsorption of polydisperse polyethylenimine onto pulp fibers," Berichte der Bunsengesellschaft für physikalische Chemie 100(6), 954-962. DOI: 10.1002/bbpc.19961000643

Ashori, A., Cordeiro, N., Faria, M., and Hamzeh, Y. (2013). "Effect of chitosan and cationic starch on the surface chemistry properties of bagasse paper," International Journal of Biological Macromolecules 58, 343-348. DOI:

10.1016/j.ijbiomac.2013.04.056

Budnyak, T. M., Pylypchuk, I. V., Tertykh, V. A., Yanovska, E. S., and Kolodynska, D. (2015). "Synthesis and adsorption properties of chitosan-silica nanocomposite prepared by sol-gel method," Nanoscale Research Letters 10, 87-96. DOI: 10.1186/s11671-014-0722-1

Carr, D., and Tokarz, M. (2006). "Silica nanoparticles build bridge to better retention, sheet formation," Pulp and Paper 80(2), 34-37. 
Cho, B. -U., Garnier, G., Van De Ven, T., and Perrier, M. (2006). “A bridging model for the effects of a dual component flocculation system on the strength of fiber contacts in flocs of pulp fibers: Implications for control of paper uniformity," Colloids and Surfaces A: Physicochemical and Engineering Aspects 287(1-3), 117-125. DOI: 10.1016/j.colsurfa.2006.03.029

Deng, H., Lin, P., Xin, S., Huang, R., Li, W., Du, Y., Zhou, X., and Yang, J. (2012). "Quaternized chitosan-layered silicate intercalated composites based nanofibrous mats and their antibacterial activity," Carbohydrate Polymers 89(2), 307-313. DOI: 10.1016/j.carbpol.2012.02.009

Deng, H., Wang, X., Liu, P., Ding, B., Du, Y., Li, G., Hu, X., and Yang, J. (2011). "Enhanced bacterial inhibition activity of layer-by-layer structured polysaccharide film-coated cellulose nanofibrous mats via addition of layered silicate," Carbohydrate Polymers 83(1), 239-245. DOI: 10.1016/j.carbpol.2010.07.042

Habibie, S., Hamzah, M., Anggaravidya, M., and Kalembang, E. (2016). "The effect of chitosan on physical and mechanical properties of paper," Journal of Chemical Engineering and Materials Science 7(1), 1-10. DOI: 10.5897/JCEMS2015.0235

Hamzeh, Y., Sabbaghi, S., Ashori, A., Abdulkhani, A., and Soltani, F. (2013). "Improving wet and dry strength properties of recycled old corrugated carton (OCC) pulp using various polymers," Carbohydrate Polymers 94(1), 577-583. DOI: 10.1016/j.carbpol.2013.01.078

Huang, C., Li, H., Liu, W., and Zhan, H. (2007). "The retention- and drainage-aid behavior of quaternary chitosan in papermaking system," Colloids and Surfaces A: Physicochemical and Engineering Aspects 297(1-3), 147-153. DOI: 10.1016/j.colsurfa.2006.10.039

Hubbe, M. A. (2005). "Microparticle programs for drainage and retention," in: Micro and Nanoparticles in Papermaking, J. M. Rodriguez (ed.), TAPPI Press, Atlanta, GA, USA, pp. 1-27.

Hubbe, M. A. (2006). "Bonding between cellulosic fibers in the absence and presence of dry-strength agents - A review," BioResources 1(2), 281-318. DOI:

10.15376/biores.1.2.Hubbe

Hwang, K. T., Jung, S. T., Lee, G. D., Chinnan, M. S., Park, Y. S., and Park, H. J. (2002). "Controlling molecular weight and degree of deacetylation of chitosan by response surface methodology," Journal of Agricultural and Food Chemistry 50(7), 18761882. DOI: 10.1021/jf011167u

Jahan, M. S., Noori, A., Ahsan, L., Chowdhury, D. A. N., and Quaiyyum, M. A. (2009). "Effects of chitosan as dry and wet strength additive in bamboo and acacia pulp," IPPTA Journal 21(2), 85-88.

Kermanian, H., Razmpour, Z., Ramezani, O., Mahdavi, S., Rahmaninia, M., and Ashtari, H. (2013). "The influence of refining history of waste NSSC paper on its recyclability," BioResources 8(4), 5424-5434. DOI: 10.15376/biores.8.4.5424-5434

Khosravani, A., Latibari, A. J., Mirshokraei, S. A., Rahmaninia, M., and Nazhad, M. M. (2010). "Studying the effect of cationic starch-anionic nanosilica system on retention and drainage," BioResources 5(2), 939-950. DOI: 10.15376/biores.5.2.939-950

Khosravani, A., and Rahmaninia, M. (2013). "The potential of nanosilica-cationic starch wet end system for applying higher filler content in fine paper," BioResources 8(2), 2234-2245. DOI: 10.15376/biores.8.2.2234-2245 
Kim, U. -J., Kim, H. -J., Choi, J. -W., Kimura, S., and Wada, M. (2017). "Cellulosechitosan beads crosslinked by dialdehyde cellulose," Cellulose 24(12), 5517-5528. DOI: $10.1007 / \mathrm{s} 10570-017-1528-\mathrm{y}$

Li, H., Du, Y., Wu, X., and Zhan, H. (2004). "Effect of molecular weight and degree of substitution of quaternary chitosan on its adsorption and flocculation properties for potential retention-aids in alkaline papermaking," Colloids and Surfaces A:

Physicochemical and Engineering Aspects 242(1-3), 1-8. DOI:

10.1016/j.colsurfa.2004.04.051

Miranda, R., Nicu, R., Bobu, E., and Blanco, A. (2016). "Efficiency of chitosan and their combination with bentonite as retention aids in papermaking," BioResources 11(4), 10448-10468. DOI: 10.15376/biores.11.4.10448-10468

Myllytie, P., Salmi, J., and Laine, J. (2009). "The influence of pH on the adsorption and interaction of chitosan with cellulose," BioResources 4(4), 1647-1662. DOI: 10.15376/biores.4.4.1647-1662

Nicu, R., Bobu, E., and Desbrières, J. (2011). "Chitosan as cationic polyelectrolyte in wet-end papermaking systems," Cellulose Chemistry and Technology 45(1), 105-111.

Nicu, R., Bobu, E., Miranda, R., and Blanco, A. (2013). "Flocculation efficiency of chitosan for papermaking applications," BioResources 8(1), 768-784. DOI: 10.15376/biores.8.1.768-784

Rahmaninia, M., Latibari, A. J., Mirshokraei, S. A., Azadfallah, M. (2008), "The influence of newspaper aging on optical properties of its de-inked pulp," Turkish Journal of Enginieering and Environmental Sciences 32(1), 35-39.

Rahmaninia, M., and Khosravani, A. (2015). "Improving the paper recycling process of old corrugated container wastes," Cellulose Chemistry and Technology 49(2), 203208.

Rahmaninia, M., Javid, E., Varshoei, A. (2016). "Process variables and the performance of cationic rosin as an internal sizing agent in recycled corrugated container pulp," BioResources 11(2), 5333-5342. DOI: 10.15376/biores.11.2.5333-5342

Rahmaninia, M., Rohi, M., Hubbe, M. A., Zabihzadeh, S. M., and Ramezani, O. (2018). "The performance of chitosan with bentonite microparticles as wet-end additive system for paper reinforcement," Carbohydrate Polymers 179, 328-332. DOI: 10.1016/j.carbpol.2017.09.036

Rohi, M., Ramezani, O., Rahmaninia, M., Zabihzadeh, S. M., and Hubbe, M. A. (2016). "Influence of pulp suspension $\mathrm{pH}$ on the performance of chitosan as a strength agent for hardwood CMP paper," Cellulose Chemistry and Technology 50(7-8), 873-878.

Saarinen, T. (2008). Adsorption Studies of Polyelectrolytes and Enzymes on Lignocellulosic Model Surfaces, Ph.D. Dissertation, Helsinki University of Technology, Helsinki, Finland.

Sabazoodkhiz, R., Rahmaninia, M., and Ramezani, O. (2017). "Interaction of chitosan biopolymer with silica nanoparticles as a novel retention/drainage and reinforcement aid in recycled cellulosic fibers," Cellulose 24(8), 3433-3444. DOI: 10.1007/s10570017-1345-3

Scott, W. E. (1996). Principles of Wet End Chemistry, TAPPI Press, Atlanta, GA, USA.

TAPPI T200 sp-01 (2001). "Laboratory beating of pulp (Valley beater method)," TAPPI Press, Atlanta, GA.

TAPPI T205 sp-02 (2002). "Forming handsheets for physical tests of pulp," TAPPI Press, Atlanta, GA. 
TAPPI T227 om-04 (2004). "Freeness of pulp (Canadian standard method)," TAPPI Press Atlanta, GA.

TAPPI T261 cm-00 (2000). "Fines fraction by weight of paper stock by wet screening," TAPPI Press, Atlanta, GA.

TAPPI T403 om-02 (2002). "Bursting strength of paper," TAPPI Press, Atlanta, GA.

TAPPI T414 om-04 (2004). "Internal tearing resistance of paper (Elmendorf-type method)," TAPPI Press, Atlanta, GA.

TAPPI T494 om-01 (2001). "Tensile properties of paper and paperboard (using constant rate of elongation apparatus)," TAPPI Press, Atlanta, GA.

TAPPI T569 pm-00 (2000). "Internal bond strength (Scott type)," TAPPI Press, Atlanta, GA.

Vikele, L., Laka, M., Sable, I., Rozenberga, L., Grinfelds, U., Zoldners, J., Passas, R., and Mauret, E. (2017). "Effect of chitosan on properties of paper for packaging," Cellulose Chemistry and Technology 51(1-2), 67-73.

Yousefhashemi, S. M., Khosravani, A., Yousefi, H. (2019). "Isolation of lignocellulose nanofiber from recycled old corrugated container and its interaction with cationic starch-nanosilica combination to make paperboard," Cellulose. DOI: 10.1007/s10570019-02562-2

Article submitted: January 19, 2019; Peer review completed: April 8, 2019; Revised version received and accepted: July 31, 2019; Published: August 7, 2019.

DOI: 10.15376/biores.14.4.7687-7701 